\title{
Validation of the test for detecting SARS- -CoV-2 antigens in the Polish population in patients with suspected SARS-CoV-2 infection
}

\author{
MATEUSZ MIEOSZI, MICHAE SŁOTA2, JAKUB JAKUBOWSKI ${ }^{3}$, PIOTR KWIATKOWSKI \\ SŁAWOMIR KASPERCZYK ${ }^{4}$, MAEGORZATA KOZŁOWSKA ${ }^{l}$, BARBARA PAWŁOWSKA ${ }^{l}$, \\ PATRYK MATUSZEK ${ }^{1}$, EWA KUTA ${ }^{5}$ \\ ${ }^{1}$ EUROIMMUN Poland Sp. z o.o., Wrocław, Poland \\ ${ }^{2}$ ARKOP Sp. z o.o., Bukowno, Poland \\ ${ }^{3}$ Department of Cardiology, Electrotherapy and Angiology, SCANMED S.A. Raciborskie Centrum Medyczne, Racibórz, Poland \\ ${ }^{4}$ Department of Biochemistry, Faculty of Medical Sciences in Zabrze, Medical University of Silesia in Katowice, Zabrze, Poland \\ ${ }^{5}$ Center of Laboratory Diagnostic, Łódź, Poland
}

\begin{abstract}
In December 2019, the World Health Organization (WHO) reported that China had accumulated pneumonia of unclear etiology in Wuhan. According to WHO recommendations, in strictly defined situations, antigen tests can be implemented into the diagnostic algorithm to reduce the number of molecular tests performed and support the rapid identification and treatment of COVID-19 patients. According to WHO recommendations, the antigen test for diagnostic use should have a sensitivity of $\geq 80 \%$ and a specificity of $\geq 97 \%$ compared to molecular tests (NAAT). Based on the comparative analysis, the sensitivity and specificity of the SARS-CoV-2 Antigen ELISA test were determined concerning the RT-PCR reference method. The sensitivity of the SARS-CoV-2 Antigen ELISA was 100\% (51/51) and the specificity was $98.84 \%$. The obtained data demonstrate that the analyzed antigen test meets both the WHO and the Ministry of Health criteria.
\end{abstract}

Key words: COVID-19, antigen detection, ELISA, SARS-CoV-2.

(Cent Eur J Immunol 2022; 47 (1): 58-62)

\section{Introduction}

Human coronaviruses are primarily responsible for mild respiratory infections. In the past, only two viruses belonging to the Coronaviridae family (SARS-CoV(-1) and MERS-CoV) caused epidemics, but their effects did not profoundly impact public health and medical infrastructure worldwide $[1,2]$.

In December 2019, the World Health Organization (WHO) reported that China had accumulated pneumonia of unclear etiology in Wuhan [3]. Shortly after that, a new etiological agent belonging to human coronaviruses, SARSCoV-2, was identified as the source of the infection [4]. It is responsible for the COVID-19 (coronavirus disease 2019) pandemic announced in March by the WHO, which unexpectedly changed the lives of millions of people around the world [5]. The COVID-19 pandemic is a rapidly spreading, extremely contagious disease much more serious than the seasonal flu [6]. By January 17, 2020, 330 million cases had been confirmed worldwide; more than 5.5 million people have died from COVID-19 disease [7]. Vaccinations have had the greatest hope in limiting the spread of the virus, reducing hospitalizations and deaths since the epidemic's outbreak [8]. While the global effects of COVID-19 were already catastrophic, there was another, fourth wave of the pandemic in autumn 2021. In the current epidemiological situation, the overriding goal of the health care system is to stop the spread of the SARS-CoV-2 virus. The therapeutic options for patients are still limited; hence laboratory diagnostics remains the primary tool in the fight against COVID-19.

Due to the rapidly growing knowledge about SARS-CoV-2 and COVID-19 pathogenesis, diagnostic improvements have undergone significant modifications several times. Initially, only molecular tests could diagnose this disease, which was relevant to important research areas for the genetic detection of SARS-CoV-2: the time-consuming procedure and high cost of determination [9-11]. The dramatically growing number of new cases in the

Correspondence: Mateusz Miłosz, EUROIMMUN Poland Sp. z o.o., ul. Widna 2A, 50-543 Wrocław, Poland, e-mail: m.milosz@euroimmun.pl Submitted: 07.12.2021, Accepted: 01.02.2022 
world has prompted specialists in infectious diseases and epidemiology to look for solutions that will improve the existing diagnostic algorithm and allow for the rapid isolation of SARS-CoV-2 infected viruses. According to WHO recommendations, in strictly defined situations, antigen tests can be implemented into the diagnostic algorithm to reduce the number of molecular tests performed and support the rapid identification and treatment of COVID-19 patients. According to WHO recommendations, the antigen test for diagnostic use should have a sensitivity of $\geq 80 \%$ and a specificity of $\geq 97 \%$ compared to molecular tests (NAAT) [12]. In the document published on November 3, 2020 by the Ministry of Health (Ministry of Health), "Possibility of using SARS-CoV-2 antigen detection tests in the COVID-19 diagnosis in Poland - Coordination Team for COVID laboratory network statement", it was emphasized that due to the severe consequences of false-negative results, the recommendation is to use antigen tests for diagnostics with a diagnostic sensitivity $\geq$ of $90 \%$ and diagnostic specificity $\geq$ of $97 \%$ concerning the validation data declared by the manufacturer [13].

Antigen tests available on the diagnostic market show significant diversity in terms of the most critical parameters, which indicate their potential usefulness in routine laboratory diagnostics. The most important international organizations, institutions, and agencies responsible for public health emphasize that when selecting an antigen test its quality should be taken into account $[14,15]$. However, knowledge of the tests for detecting SARS-CoV-2 virus antigens is still limited due to there being only a few published independent comparative studies. Therefore, the research aimed to independently evaluate the commercially available antigen test (SARS-CoV-2 Antigen ELISA) in comparison to the reference method - RT-PCR.

\section{Material and methods}

\section{Patients samples}

One hundred thirty-seven samples of patients suspected of SARS-CoV-2 infection were collected from 17 November to 20 November 2020. Patients were swabbed from the nasopharynx using a swab set. In order to protect the material, swabs were placed in the transport buffer and stored at $+4^{\circ} \mathrm{C}$ for a maximum of 48 hours.

Ninety six patients $(70.07 \%)$ had a fever, cough, runny nose, muscle pain, and general weaknesses. Thirty-five (25.54\%) were asymptomatic; they were from contact with positive PCR SARS-CoV-2 patients. Six patients (4.39\%) were unknown.

The residual material after RT-PCR testing was used to validate the EUROIMMUN antigen test. All procedures related to collecting and analyzing samples obtained from patients were carried out in a diagnostic laboratory with an ISO 15189 accreditation certificate.

\section{Diagnostic kits}

\section{$R T-P C R$}

The instructions provided by the manufacturer were followed to carry out extraction of SARS-CoV-2, RT-PCR genetic material and analysis of the results. RNA was extracted and purified using the RNA isolation kit (RNeasy Plus Mini, Qiagen). Reverse transcription, amplification and detection of RNA isolated from the sample and analysis of the results were performed using the EURORealTime SARS-CoV-2 test kit (EUROIMMUN) and EURORealTime software Analysis (EUROIMMUN). The EURORealTime PCR SARS-CoV-2 assay enables the parallel detection in a single reaction of two particular gene sequences: ORF1ab and N-Gen. The test kit includes the Internal Amplification Control, which also serves as an inhibition control, and the SARS-CoV-2 Positive Control serves as an external control for each test run. RT-PCR was performed for 45 cycles on a Rotor-Gene Q thermal cycler, Qiagen. A cycle threshold $(\mathrm{Ct})$ was assigned to each PCR reaction, and the amplification curve was evaluated. Based on the internal validation of the EURORealTime PCR SARS-CoV-2 test and literature data, samples with $\mathrm{Ct} \leq 31$ were considered positive.

\section{Antigen test}

The transport media with the swabs were placed after the material was collected were used in parallel for testing for SARS-CoV-2 virus antigens. For this purpose, the SARS-CoV-2 Antigen ELISA test kit (EUROIMMUN) was used, in which the 96-well microplate was coated with monoclonal antibodies against the SARS-CoV-2 virus protein. The test was performed using a device enabling full automation of incubation - Analyzer I-2P (EUROIMMUN). The incubation procedure was followed according to the manufacturer's instructions included with the test kit. Before testing, the samples were diluted $(1: 1.5)$ in the lysis buffer supplied with the kit, then mixed and incubated $(5 \mathrm{~min})$. The results were read spectrophotometrically at $450 \mathrm{~nm}$ and a reference wavelength between $620 \mathrm{~nm}$ and $650 \mathrm{~nm}$. The results were assessed semi-quantitatively by calculating the value of the so-called ratio coefficient, i.e. the ratio of extinction of the analyzed sample to the extinction of the "cut-off" calibrator. Interpretation of the results: ratio $<0.5$ - negative result, ratio $\geq 0.5$ and $<0.6$ - borderline result, ratio $\geq 0.6$ - positive result. As part of the validation analysis, the samples located in the border zone were classified as positive.

\section{Results}

\section{Comparative analysis of the antigen test with RT-PCR}

The study was carried out on 137 nasopharyngeal swabs, of which $51(37.2 \%)$ samples were positive and 


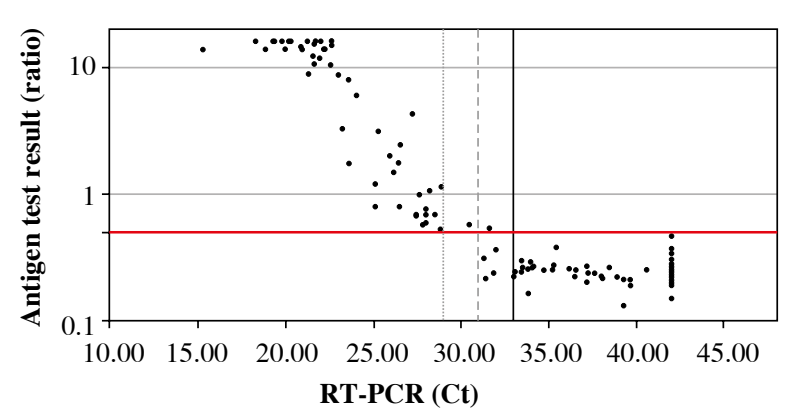

Fig. 1. Level of SARS-CoV-2 antigen in the tested sample plotted against the result obtained with the reference method (RT-PCR). According to the RT-PCR evaluation criteria adopted in the laboratory, the results for which $\mathrm{Ct} \leq 31$ are considered positive

$86(62.8 \%)$ negative, as determined by the RT-PCR reference method. Samples for which $\mathrm{Ct} \leq 31$ were considered positive. The median $\mathrm{Ct}$ of the positive samples was 23.77 (range 15.31-30.54).

In parallel, all samples were analyzed by the antigen test. Fifty-two samples were considered positive, 85 samples were negative. One false positive was obtained (ratio 0.54 , Ct 31.65). The median ratio in the positive samples for RT-PCR was 15.90 (range: 0.54-40.91), and negative samples were 0.25 (range: $0.13-0.54$ ). The mean level of antigen in the positive samples (concerning RT-PCR) was significantly higher than in the negative samples (Fig. 1).

Table 2. Sensitivity and specificity of the antigen test depending on the Ct cut-off in RT-PCR

\begin{tabular}{|c|c|c|c|c|}
\hline & & $\begin{array}{c}(+) \\
\text { RT-PCR } \\
(\text { Ct } \leq 29)\end{array}$ & $\begin{array}{c}(+) \\
\text { RT-PCR } \\
(\text { Ct } \leq \text { 31) }\end{array}$ & $\begin{array}{c}(+) \\
\text { RT-PCR } \\
(\mathbf{C t} \leq \mathbf{3 3})\end{array}$ \\
\hline \multirow{2}{*}{$\begin{array}{l}\text { SARS-CoV-2 } \\
\text { Antigen ELISA }\end{array}$} & Sensitivity & $100 \%$ & $100 \%$ & $91.23 \%$ \\
\hline & Specificity & $97.70 \%$ & $98.84 \%$ & $100 \%$ \\
\hline
\end{tabular}

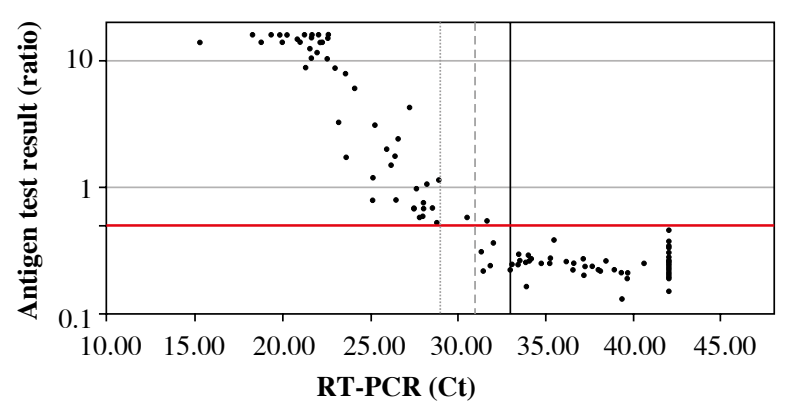

Fig. 2. Correlation of the SARS-CoV-2 antigen test Antigen ELISA (EUROIMMUN) (ratio) with the results obtained by the reference RT-PCR method depending on the $\mathrm{Ct}$ value. $\mathrm{Ct}=29$ - dotted line, $\mathrm{Ct}=31-$ dashed line, $\mathrm{Ct}=33-$ solid line
Table 1. Parameters of the SARS-CoV-2 Antigen ELISA test

\begin{tabular}{lcccc}
\hline & & \multicolumn{3}{c}{ RT-PCR $(\mathbf{C t} \leq \mathbf{3 1})$} \\
\hline & & Positive & Negative & $\sum$ \\
\hline SARS- & Positive & 51 & 1 & 52 \\
\cline { 2 - 5 } CoV-2 & Negative & 0 & 85 & 85 \\
\cline { 2 - 5 } Antigen & $\Sigma$ & 51 & 86 & 137 \\
\hline ELISA & & Sensitivity & Specificity & Compatibility \\
\hline & & $100 \%$ & $98.84 \%$ & $99.27 \%$ \\
\hline
\end{tabular}

Parameters of the SARS-CoV-2 Antigen ELISA test depending on the Ct cut-off point in $R T$-PCR

\section{Sensitivity and specificity of the SARS-CoV-2 ELISA antigen test}

Based on the comparative analysis, the sensitivity and specificity of the SARS-CoV-2 Antigen ELISA test were determined concerning the RT-PCR reference method. Sensitivity was determined based on the ratio of positive results determined with the antigen test compared to all positive results obtained with RT-PCR. Specificity was determined based on the ratio of the negative results determined with the antigen test compared to all negative results obtained with RT-PCR. The sensitivity of the SARS-CoV-2 Antigen ELISA was $100 \%$ (51/51) and the specificity was $98.84 \%$ (85/86) (Table 1$)$.

Based on the results of the comparative study, the sensitivity and specificity of the antigen test were determined depending on the cut-off point of the $\mathrm{Ct}$ value in the reference test (RT-PCR) (Table 2, Fig. 2).

\section{Discussion}

As part of this work, comparative studies of the antigen test, i.e. SARS-CoV-2 Antigen ELISA with the RT-PCR genetic test, i.e. EURORealTime SARS-CoV-2, were performed. To our knowledge, this is the first report of this type on the clinical validation of an ELISA-based antigen test conducted in Poland. The SARS-CoV-2 Antigen ELISA test was one of the first in Europe to receive the CE-IVD certificate, which is awarded to medical products that meet the safety standards established by the European Union. Therefore, it is commercially available on the medical market and can be used for in vitro diagnosis of COVID-19.

According to data provided by the manufacturer, the test is characterized by sensitivity of $93.6 \%$ and specificity of $100 \%$, which was determined based on a series of carefully characterized samples. An independent analysis carried out as part of this study showed that the sensitivity of the SARS-CoV-2 Antigen ELISA test is $100 \%$ and specificity if $98.84 \%$ for the RT-PCR reference method. 
The obtained data confirm that the analyzed antigen test meets both the WHO and the Ministry of Health criteria.

Available antigen tests detect proteins that are critical structural elements of the virus and are involved in the pathogenesis of infection. The SARS-CoV-2 Antigen ELISA test was used to detect the $\mathrm{N}$ protein in the tested sample, which is part of the nucleocapsid structure. As a result of the analysis, it was shown that the level of viral antigen in the tested sample depended on the $\mathrm{Ct}$ value obtained in the RT-PCR test. It has been observed that the lower the $\mathrm{Ct}$ value, the higher the antigen level. Moreover, the antigen test has been shown to have the highest sensitivity for samples with a low $\mathrm{Ct}$ value. A high $\mathrm{Ct}$ value indicates a low viral load in the epithelium of the upper respiratory tract, which may occur at a very early stage of infection (immediately after contact with the virus, before the onset of clinical symptoms) or in the late stage of the disease when the replicative activity of the virus is reduced [16]. Therefore, antigen tests are most applicable in the symptomatic phase of COVID-19, as the viral load in the epithelium of the upper respiratory tract is then the highest [17]. According to the current knowledge about the SARS-CoV-2 virus transmission routes, the viral load in the respiratory tract correlates with infectivity [18]. In the current epidemiological situation, antigen tests are the optimal diagnostic solution enabling early isolation of infected people and inhibition of further spread of SARS-CoV-2 in the population.

The antigen test used in the comparative study is based on the ELISA method, which has been used for years as a reliable diagnostic tool for the detection of antigens or specific antibodies in many infectious diseases [19]. The use of the well-known and proven ELISA method in the context of a new pathogen is the optimal solution ensuring repeatability of the obtained results and high precision of the test. Automatic, objective spectrophotometric reading of the result eliminates the risk of human error. In addition, in the face of the pandemic and the enormous scale of tests for SARS-CoV-2 infection, the possibility of fully automating the incubation process is an undoubted advantage. The high throughput of automatic systems makes the SARS-CoV-2 Antigen ELISA test a suitable tool for testing large groups of patients suspected of COVID-19 - this allows for natural relief of genetic laboratories in large-scale research.

Complementing the diagnosis of COVID-19 in symptomatic patients with SARS-CoV-2 antigen detection tests reduces the waiting time for the test result and improves the process of referring patients for isolation [14]. As the number of COVID-19 cases increases exponentially, the rapid isolation of patients is key to limiting further SARSCoV-2 virus transmission and then gradually normalizes the health system. Antigen testing seems to be the missing link in the fight against the COVID-19 pandemic. According to the manufacturer's assurances, the test should detect patients infected with the Omicron variant. Preliminary studies on the sequence of the new variant show that the most changes can be observed within the $\mathrm{S}$ gene [20].

In an era when the SARS-CoV-2 virus spreads unpredictably and rapidly, countries are looking for testing strategies that will ensure maximum detection, taking into account places with limited availability of health care and lower testing costs. India has proposed a solution in which diagnostics begins with the RAT (rapid antigen test). If the result is positive, infection is reported, and if the result is negative and the patient symptomatic, RT-PCR is performed. The solution allowed for broader testing in rural areas and a significant reduction in the cost and time of diagnostics [21]. When proposing this approach, one should bear in mind that the highest possible sensitivity should characterize the selected RAT test because it gives the possibility of obtaining a negative result; otherwise this approach will generate a significant false-negative rate in individuals who may be asymptomatic. At this point, we can use an analogy with the principles of diagnosing Lyme disease. In the case of Borrelia infection, a two-stage diagnosis is obligatory - first, a highly sensitive screening ELISA test should be performed, which gives factual information with a negative result. A particular confirmation test, LINE BLOT, is recommended if the screening test is positive.

\section{The authors declare no conflict of interest.}

\section{References}

1. Pyrć K (2015): Ludzkie koronawirusy. Postępy Nauk Medycznych 28, no. 4B: 48-54.

2. Pancer KW (2018): Pandemiczne koronawirusy człowieka - charakterystyka oraz porównanie wybranych właściwości HCoV-SARS i HCoV-MERS. Post Mikrobiol 57: 22-32.

3. World Health Organization (2020): WHO Statement Regarding Cluster of Pneumonia Cases in Wuhan, China (online) (accessed 16.12.2020).

4. Gralinski LEMV (2020): Return of the coronavirus: 2019nCoV. Viruses 135.

5. World Health Organization (2020): https://www.who.int/ director-general/speeches/detail/who-director-general-sopening-remarks-at-the-media-briefing-on-covid-19---11march-2020. 11.03.2020b (online) (accessed 16.12.2020).

6. Marcinkiewicz J, Witkowski JM, Olszanecki R (2021): The dual role of the immune system in the course of COVID-19. The fatal impact of the aging immune system. Cent Eur J Immunol 46: 1-9.

7. Worldometers.info, Dover, Delaware, U.S.A., 17 January, 2022.

8. Kyriakidis N, López-Cortés A, Vásconez González E, et al. (2021): SARS-CoV-2 vaccines strategies: a comprehensive review of phase 3 candidates. NPJ Vaccines 6: 28.

9. Lai CC, Wang CY, Ko WC, et al. (2020): In vitro diagnostics of coronavirus disease 2019: Technologies and application. J Microbiol Immunol Infect 54: 164-174.

10. World Health Organization (2020): Laboratory testing for coronavirus disease (COVID-19) in suspected human cases: interim guidance, 19.03.2020. 
11. Corman VM, Landt O, Kaiser M, et al. (2020): Detection of 2019 novel coronavirus (2019-nCoV) by real-time RT-PCR. Euro Surveill 25: 2000045.

12. World Health Organization (2020): Antigen-detection in the diagnosis of SARS-CoV-2 infection using rapid immunoassays, 11.09.2020 (online) (accessed 16.12.2020).

13. Ministerstwo Zdrowia (2020): Stanowisko Zespołu do spraw koordynacji sieci laboratoriów COVID w sprawie możliwości wykorzystania testów wykrywających antygen SARS-CoV-2 w diagnostyce COVID-19 w Polsce, 03.11.2020 (online) (accessed 16.12.2020).

14. Centers for Disease Control and Prevention (2020): Interim Guidance for Antigen Testing for SARS-CoV-2, 05.12.2020. Available: https://www.cdc.gov/coronavirus/2019-ncov/ lab/resources/antigen-tests-guidelines.html (accessed 16.12.2020).

15. Flisiak R, Parczewski M, Horban A, et al. (2020): Zalecenia diagnostyki i terapii zakażeń SARS-CoV-2 Polskiego Towarzystwa Epidemiologów i Lekarzy Chorób Zakaźnych, 13.10.2020 (online) (accessed 16.12.2020).

16. He X, Lau EHY, Wu P, et al. (2020): Temporal dynamics in viral shedding and transmissibility of COVID-19. Nat Med 26: 672-675.

17. Guglielmi G (2020): Fast coronavirus tests: what they can and can't do. Nature 585: 496-498.

18. Wölfel R, Corman VM, Guggemos W (2020): Virological assessment of hospitalized patients with COVID-2019. Nature 581: 465-469.

19. Yoshihara N (1995): ELISA for diagnosis of infections by viruses. Nihon Rinsho 9: 2277-2282.

20. Wang L, Cheng G (2022): Sequence analysis of the emerging SARS-CoV-2 variant Omicron in South Africa. J Med Virol 94: 1728-1733.

21. Business Standard (2022): Business Standard (online). Available: https://www.business-standard.com/article/current-affairs/omicron-why-a-potential-covid-19-surge-might-needhybrid-testing-121121900124_1.html (accessed 20.01.2022). 